https://doi.org/10.35336/VA-2021-2-18-27

ПЯТИЛЕТНЯЯ ВЫЖИВАЕМОСТЬ И БИОМАРКЕРЫ СИМПАТО-АДРЕНАЛОВОЙ, НЕЙРОГУМОРАЛЬНОЙ, ИММУННОЙ АКТИВАЦИИ, ФИБРОЗА У БОЛЬНЫХ С РАННИМ И ПОЗДНИМ СУПЕРОТВЕТОМ НА СЕРДЕЧНУЮ РЕСИНХРОНИЗИРУЮЩУЮ ТЕРАПИЮ В.А.Кузнецов, Т.Н.Енина, Е.А.Горбатенко, А.М.Солдатова, Н.Е.Широков, Т.И.Петелина, Л.А.Винемарк Тюменский кардиологический научный центр, Томский национальный исследовательский медицинский центр Российской академии наук, Россия, г. Тюмень, ул. Мельникайте, д. 111

Цель: оценить выживаемость во взаимосвязи с биомаркерами активности процесса фиброза, симпато-адреналовой, нейрогуморальной, иммунной активации у суперреспондеров (СР; уменьшение конечно-систолического объема левого желудочка (КСОЛЖ) $\geq 30 \%$ ) с различным сроком ответа на сердечную ресинхронизирующую терапию (СРТ).

Материал и методы: 82 СР (60,4 99,3 года; 66 (80,5\%) мужчины; 45 (54,9\%) с ишемической болезнью сердца) по сроку максимального снижения КСОЛЖ разделены на группы: 1 (n=19) - $\leq 24$ мес. (14,0[8,0;21,0]), 2 (n=63) - >24 мес. (59[43,0;84,0]). В динамике изучались эхокардиографические (ЭхоКГ) параметры, плазменные уровни адреналина (Адр), норадреналина (НАдр), интерлейкинов (ИЛ) 1 $\beta, 6,10$, ФНО- $\alpha$, NT-proBNP, MMP-9, TIMP 1, 4. Методом Каплан-Мейера оценили 5-летнюю выживаемость. ROC-анализ и логистическую регрессию применили для выявления факторов позднего ответа на СРТ.

Результаты. Группы исходно не различались по клиническим и ЭхоКГ параметрам. Исходно во 2 гр. выявлены большие уровни Адр ( $\mathrm{p}=0,049)$. Степень изменения НАдр в группах на фоне СРТ была противоположной: повышалась в 1 гр. и снижалась во 2 гр. (р=0,015), что было ассоциировано с лучшим обратным ремоделированием сердца (меньшие конечно-систолические и конечно-диастолические размеры ЛЖ, КСОЛЖ, конечно-диастолический объем ЛЖ), снижением активности иммунного воспаления (снижение уровня ИЛ-1 $\beta, 6,10$, ФНО- $\alpha$ ) и фиброзирования (снижение TIMP-1, повышение ММР-9/ТIMР-1). Точка разделения НАдр 2,55 нг/мл соответствовала наибольшей чувствительности (80\%), специфичности (60\%), $\mathrm{AUC}=0,693$ ( $\mathrm{p}=0,011)$ в предсказании позднего ответа на СРТ. Доля пациентов с НАдр $<2,55$ нг/мл составила 21,1\% в 1 гр. и 59,7\% во 2 гр. (р=0,003), средний период наблюдения 45,8 $\pm 0,3$ мес. и

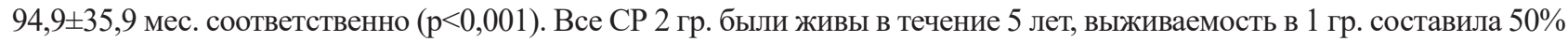
(Log-Rank test < 0,001). С поздним ответом на СРТ был связан НАдр (ОШ 8,0 (95\% ДИ 1,5-42,8), p=0,015).

Заключение. Поздний ответ на СРТ сопровождался увеличением продолжительности жизни, лучшей 5-летней выживаемостью, ассоциированными с большим обратным ремоделированием сердца, снижением активности процесса развития фиброза, иммунной, нейро-гуморальной и симпато-адреналовой активации. При уровне НАдр менее 2,55 нг/мл шанс позднего ответа увеличивался в 8 раз.

Ключевые слова: хроническая сердечная недостаточность; сердечная ресинхронизирующая терапия; суперреспондеры; катехоламины; иммунное воспаление; фиброз

Конфликт интересов: не заявляется

Рукопись получена: 03.06.2021 Исправленная версия получена: 26.07.2021 Принята к публикации: 27.07 .2021 Ответственный за переписку: Енина Татьяна Николаевна, E-mail: Enina@infarkta.net

Кузнецов В.A. - ORCID ID 0000-0002-0246-9131, Енина T.Н. - ORCID ID 0000-0002-7443-2952, Горбатенко Е.A. ORCID ID 0000-0003-3675-1503, Солдатова A.M. - ORCID ID 0000-0001-5389-0973, Широков H.E. - ORCID ID 0000-0002-4325-2633, Петелина Т.И. - ORCID ID 0000-0001-6251-4179, Винемарк Л.А. - ORCID ID

Для цитирования: Кузнецов ВА, Енина ТН, Горбатенко ЕА, Солдатова АМ, Широков НЕ, Петелина ТИ, Винемарк ЛА. Пятилетняя выживаемость и биомаркеры симпато-адреналовой, нейрогуморальной, иммунной активации, фиброза у больных с ранним и поздним суперответом на сердечную ресинхронизирующую терапию. Вестник аритмологии. 2021;28(2):18-27. https://doi.org/10.35336/VA-2021-2-18-27.

\title{
FIVE-YEAR SURVIVAL AND BIOMARKERS OF SYMPATHO-ADRENAL, NEUROHUMORAL, IMMUNE ACTIVATION, FIBROSIS IN PATIENTS WITH EARLY AND LATE SUPERRESPONSE TO CARDIAC RESYNCHRONIZATION THERAPY
}

V.A. Kuznetsov, T.N. Enina, E.A. Gorbatenko, A.M. Soldatova, N.E. Shirokov, T.I. Petelina, L.A. Winemark Tyumen Cardiology Research Center, Tomsk National Research Medical Center, Russian Academy of Science, Russia, Tyumen, 111 Melnikayte str

Aim. To estimate survival regarding biomarkers of sympatho-adrenal, neurohumoral, immune activation, fibrosis in superresponders (SR; left ventricle end systolic volume (LVESV) decrease $\geq 30 \%$ ) with different cardiac resynchronization therapy (CRT) response time. 
Methods. 82 SR (80.5\% men; mean age $60.4 \pm 9.3 ; 45(54.9 \%)$ with CAD) were divided according to period of LVESV maximum decrease: Gr.1 (n=19)- <24months (14.0 [8.0; 21.0]), Gr.2 ( $\mathrm{n}=63)->24$ months (59[43.0; 84.0]). Dynamics of echocardiography, adrenaline (ADR) plasma levels, norepinephrine (NE), interleukins (IL) $1 \beta, 6,10$, TNF- $\alpha$, NT-proBNP, MMP-9, TIMP-1, 4, were examined. Five-year survival was estimated by Kaplan-Meier method. ROC analysis and logistic regression were applied to identify late CRT response factors.

Results. Initially, groups didn't differ by clinical and echocardiographic findings. At baseline, Gr.2 had larger ADR $(p=0.049)$ and NE $(p=0.061)$. Rate of change in NE was opposite in groups during CRT: $\triangle N E$ increased in Gr.1 and decreased in Gr.2. ( $\mathrm{p}=0.015$ ), which was associated with better reverse cardiac remodeling (lower LV end systolic diameter, LV end diastolic diameter, LVESV, LV end diastolic volume), decrease in activity of immune inflammation (decrease in levels of IL-1 $\beta, 6,10$, TNF- $\alpha$ ) and fibrosis formation (decrease in TIMP- 1, enhancement of MMP-9/TIMP-1). Cut-off value of $2.55 \mathrm{ng} / \mathrm{ml}$ for NE complied with the highest sensitivity $(80 \%)$, specificity $(60 \%), \mathrm{AUC}=0.693$ ( $\mathrm{p}=0.011)$ for predicting late CRT response. Proportion of patients with $\mathrm{NE}<2.55 \mathrm{ng} / \mathrm{ml}$ was $21.1 \%$ in Gr.1 and $59.7 \%$ in Gr.2, (p=0.003), mean follow-up period was $45.8 \pm 0.3$ and $94.9 \pm 35.9$ months $(\mathrm{p}<0.001)$, respectively All SR of Gr.2 were alive within 5 years, survival rate was $50 \%$ in Gr.1 (Log-Rank test $<0.001)$. NE was associated with late CRT response (OR 8.0 (95\%CI 1.5-42.8), p=0.015).

Conclusion. Late CRT response was accompanied by increased life expectancy, better 5-year survival, associated with greater reverse cardiac remodeling, decreased fibrosis activity, immune, neurohumoral, sympathoadrenal activation. When NE level was less than $2.55 \mathrm{ng} / \mathrm{ml}$, probability of late response increased 8-fold.

Key words: congestive heart failure; cardiac resynchronization therapy; superresponse; catecholamines; immune inflammation; fibrosis

Conflicts of Interests: nothing to declare

Received: 03.06.2021 Revision Received: 26.07.2021 Accepted: 27.07.2021

Corresponding author: Tatyana Enina, E-mail: Enina@infarkta.net

Kuznetsov V.A. - ORCID ID 0000-0002-0246-9131, Enina T.N. - ORCID ID 0000-0002-7443-2952, Gorbatenko E.A. ORCID ID 0000-0003-3675-1503, Soldatova A.M. - ORCID ID 0000-0001-5389-0973, 0000-0001-5389-0973, Shirokov N.E. - ORCID ID 0000-0002-4325-2633, Petelina T.I. - ORCID ID 0000-0001-6251-4179, Winemark L.A. - ORCID ID

For citation: Kuznetsov VA, Enina TN, Gorbatenko EA, Soldatova AM, Shirokov NE, Petelina TI, Winemark LA. Five-year survival and biomarkers of sympatho-adrenal, neurohumoral, immune activation, fibrosis in patients with early and late superresponse to cardiac resynchronization therapy. Journal of Arrhythmology. 2021;28(2):18-27. https://doi. org/10.35336/VA-2021-2-18-27.

Сердечная ресинхронизирующая терапия (СРТ) является одним из наиболее эффективных методов лечения хронической сердечной недостаточности $(\mathrm{XCH})$ с широким комплексом QRS на фоне оптимальной медикаментозной терапии [1]. Существует широкая вариабельность степени обратного ремоделирования левого желудочка на фоне СРТ. По данным литературы приблизительно у одной трети пациентов СРТ не сопровождается благоприятным ответом, в то время как у 10-25\% больных сердечная функция восстанавливается почти до нормальных параметров [2]. Эта группа пациентов получила в литературе название «суперреспондеров» (CР). В качестве критерия «суперответа» наиболее часто используется динамика фракции выброса левого желудочка (ФВЛЖ) [3] и конечно-систолического объема левого желудочка (КСОЛЖ) [4]. Значительное улучшение функции левого желудочка на фоне СРТ сопровождается снижением смертности, частоты повторных госпитализаций, желудочковых аритмий, мотивированных срабатываний кардиовертера-дефибриллятора $[2,3,5]$. Сроки наступления ответа на СРТ значительно варьируются и индивидуальны. Установлена ассоциация более позднего ответа на СРТ с лучшим прогнозом [6]. Мало информации о механизмах суперответа на СРТ. В основном в литературе обсуждают улучшение электромеханической функции [7]. Не изучена взаимосвязь выживаемости у больных с различным сроком суперответа на
СРТ с ключевыми механизмами патогенеза ХСН - симпато-адреналовой, иммунной, нейро-гуморальной активацией, фиброобразованием. В связи с чем проведение нашего исследования весьма актуально.

Цель исследования: оценить выживаемость во взаимосвязи с биомаркерами активности процесса фиброза, симпато-адреналовой, нейрогуморальной, иммунной активации у суперреспондеров (уменьшение КСОЛЖ $\geq 30 \%$ ) с различным сроком ответа на сердечную ресинхронизирующую терапию.

\section{МАТЕРИАЛ И МЕТОДЫ ИССЛЕДОВАНИЯ}

\section{Пациенты и критерии отбора для имплантации СРТ-устройств}

В исследование последовательно с 2003 по 2017 гг. было включено 82 СР на СРТ (с уменьшением КСОЛЖ $\geq 30 \%$ ) из «Регистра проведенных операций сердечной ресинхронизирующей терапии» (Свидетельство о государственной регистрации базы данных № 2010620077 от 1 февраля 2010 г.), который ведется в научном кардиологическом центре с 2003 г. Клиническая характеристика пациентов, включенных в исследование, представлена в табл. 1, 2. Средний возраст больных составил 60,4 99,3 года, 66 (80,5\%) из которых были мужчины преимущественно с ХСН ишемического генеза - 45 (54,9\%). Диагноз ХСН выставляли на ос- 
новании клинических рекомендаций по диагностике и лечению ХСН. СРТ-устройства с функцией кардиовертер-дефибриллятора были имплантированы 53 (64,6\%) пациентам. Больные подписывали информированное согласие на проведение исследования, которое было одобрено этическим комитетом. Критериями отбора больных на имплантацию устройств для СРТ были: XCH II-IV функционального класса (ФК), ФВЛЖ менее или равная 35\%, признаки внутри- и/или межжелудочковой диссинхронии по данным эхокардиографии (ЭхоКГ); длительность комплекса QRS $\geq 120$ мс.

\section{Эхокардиография}

ЭхоКГ проводили на аппарате Philips IE-33 (США) с оценкой параметров согласно стандартным критериям. ФВЛЖ измеряли по методу Simpson. C 2005 г. для направления на СРТ был использован протокол госпиталя Св. Марии (Лондон) [8], в котором выделены основные и дополнительные критерии. К основным критериям отнесены: ХCH класс III/IV (NYHA), оптимальная лекарственная терапия, ФВЛЖ $<35 \%$ (измеренная по Симпсону), исключение обратимых причин систолической сердечной недостаточности, оптимальная реваскуляризация. Дополнительные критерии разделены на большие и малые. К большим дополнительным критериям относятся: признаки внутрижелудочковой диссинхронии, определенные с помощью тканевой спектральной допплерографии: увеличение дисперсии внутрижелудочкового механического сокращения >55 мс; признаки комбинации внутри- и межжелудочковой диссинхронии: сумма внутри и межжелудочковой дисперсии $>100$ мс (при этом дисперсия опередляется как разница по времени между наиболее ранним и наиболее поздним сокращением сегмента). К малым дополнительным критериям отнесены: признаки внутрижелудочковой диссинхронии - внутрижелудочковая дисперсия $>40$ мс; признаки межжелудочковой диссинхронии - межжелудочковая дисперсия >40 мс; уменьшение времени наполнения левого желудочка $<40 \%$ среднего цикла (допплерография трансмитрального кровотока); период аортального предвыброса $>140$ мс (допплерография аортального кровотока); межжелудочковая механическая задержка $>40$ мс (допплерография аор- тального и пульмонального кровотоков); QRS >130 мс. Для имплантации СРТ-устройств необходимо иметь все основные критерии и несколько дополнительных: 2 больших или 1 большой +3 малых или 4 малых. Первоначально величина комплекса QRS >130 мс была включена в дополнительные критерии, однако, в 2005 г. была исключена из списка.

\section{Тест 6-минутной ходьбы и суточное мониторирование ЭКГ}

ФК определялся с учетом теста 6-минутной ходьбы и клинических критериев классификации NYHA. Суточное мониторирование ЭКГ (СМЭКГ) было выполнено на аппарате ИНКАРТ (Санкт-Петербург, Россия).

\section{Лабораторные исследования}

Плазменные уровни адреналина (Адр), норадреналина (НАдр), N-концевого фрагмента натрийуретического пептида (NT-proBNP), интерлейкинов (ИЛ)-1b, ИЛ-6, ИЛ-10, ФНО- $\alpha$, матриксной металлопротеиназы 9 (ММР9) и тканевых ингибиторов металлопротеиназ (ТIMP-1 и

Таблица 1.

Клиническая характеристика больных

\begin{tabular}{|c|c|c|c|c|}
\hline \multicolumn{2}{|l|}{ Показатель } & $\begin{array}{c}\text { I группа } \\
(<24 \text { мес, } n=19)\end{array}$ & $\begin{array}{c}\text { II группа } \\
(>24 \text { мес, } n=63)\end{array}$ & $\begin{array}{c}\text { Р между } \\
\text { группами }\end{array}$ \\
\hline \multicolumn{2}{|c|}{ Срок лучшего ответа, мес } & $13,5 \pm 7,0$ & $63,5 \pm 26,3$ & $<0,001$ \\
\hline \multicolumn{2}{|c|}{ Средний возраст, годы } & $58,8 \pm 7,4$ & $60,9 \pm 9,8$ & 0,326 \\
\hline \multicolumn{2}{|l|}{ Мужчины, \% } & $15(78,9)$ & $51(81,0)$ & 0,847 \\
\hline \multicolumn{2}{|c|}{ Ишемическая болезнь сердца, \% } & $11(57,9)$ & $34(54,0)$ & 0,763 \\
\hline \multicolumn{2}{|l|}{ ПИКС, \% } & $3(15,8)$ & $17(27,0)$ & 0,811 \\
\hline \multicolumn{2}{|l|}{ АКШ, \% } & 0 & $3(4,8)$ & 0,333 \\
\hline \multicolumn{2}{|l|}{ ЧКВ, \% } & $3(15,8)$ & $9(14,3)$ & 0,871 \\
\hline \multirow{3}{*}{$\begin{array}{l}\text { Функциональный } \\
\text { класс* сердечной } \\
\text { недостаточности, \% }\end{array}$} & II & $10(52,7)$ & $29(46,0)$ & \multirow{3}{*}{0,831} \\
\hline & III & $7(36,8)$ & $25(39,7)$ & \\
\hline & IV & $2(10,5)$ & $9(14,3)$ & \\
\hline \multicolumn{2}{|c|}{ Артериальная гипертензия, \% } & $14(73,7)$ & $48(76,2)$ & 0,824 \\
\hline \multicolumn{2}{|c|}{ Фибрилляция предсердий, \% } & $10(52,6)$ & $34(54,0)$ & 0,918 \\
\hline \multirow{3}{*}{$\begin{array}{l}\text { Общее количество } \\
\text { ЖЭ }\end{array}$} & исходно & $75,0[7,0 ; 2027,0]$ & $316,5[17,3 ; 841,8]$ & 0,707 \\
\hline & динамика & $286,0[5,0 ; 1317,0]$ & $116,0[6,0 ; 846,5]$ & 0,603 \\
\hline & $\mathrm{P} * *$ & 0,551 & 0,011 & \\
\hline \multirow{3}{*}{$\begin{array}{l}\text { Количество ЖЭ в } \\
\text { час }\end{array}$} & исходно & $3,8[0,4 ; 97,8]$ & $13,5[0,8 ; 36,5]$ & 0,862 \\
\hline & динамика & $27,7[0,2 ; 112,7]$ & $5,5[0,3 ; 41,6]$ & 0,466 \\
\hline & $\mathrm{P} * *$ & 0,875 & 0,036 & \\
\hline \multicolumn{2}{|l|}{ РЧА AB, \% } & $6(31,6)$ & $20(31,7)$ & 0,989 \\
\hline \multicolumn{2}{|l|}{ Сахарный диабет, \% } & $3(15,8)$ & $4(6,4)$ & 0,238 \\
\hline \multicolumn{2}{|l|}{ Ожирение, \% } & $12(63,2)$ & $26(41,3)$ & 0,094 \\
\hline \multicolumn{2}{|c|}{ Индекс массы тела (кг/м²) } & $31,4 \pm 5,5$ & $29,8 \pm 6,3$ & 0,289 \\
\hline \multicolumn{2}{|c|}{ Длительность QRS (мс) } & $160,4 \pm 41,0$ & $144,2 \pm 40,6$ & 0,172 \\
\hline \multicolumn{2}{|l|}{ ПБЛНПГ, \% } & $13(68,4)$ & $36(57,1)$ & 0,380 \\
\hline \multicolumn{2}{|c|}{ Тест 6-минутной ходьбы (м) } & $327,8 \pm 95,2$ & $304,9 \pm 101,4$ & 0,427 \\
\hline
\end{tabular}

Примечание: ПИКС - постинфарктный кардиосклероз; АКШ- аорто-коронарное шунтирование; ЧКВ - чрескожное коронарное вмешательство; **- по Нью-Йоркской классификации; Р* - достоверность различий в группе, ЖЭ - желудочковая экстрасистолия; РЧА АВ - радиочастотная аблация АВ соединения; ПБЛНПГ полная блокада левой ножки пучка Гиса. 
TIMP-4) ММР-9 были исследованы методом твердофазного хемилюминесцентного иммуноферментного анализа (сэндвич-метод) на анализаторе IMMULITE 1000 (Siemens Diagnostics, CША). Рассчитывали коэффициенты ММР-9/ТIMP-1 и ММР-9/ТIMР-4. Определение высокочувствительной фракции С-реактивного белка (СРБ) в сыворотке крови было проведено иммунотурбидиметрическим методом с использованием аналитических наборов C-REACTIVE PROTEIN hs (BioSystems, Испания) на анализаторе Clima MC-15 (Испания).

Исследования проводили исходно, через 1, 3, 6 месяцев и каждые последующие 6 месяцев после имплантации СРТ-устройств.

\section{Статистическая обработка}

Статистический анализ проводился с помощью пакета прикладных программ SPSS 21 (SPSS Inc., Chicago, IL, USA). Нормальность распределения оценивали по методу Колмогорова-Смирнова. При нормальном распределении результаты представлены в виде $\mathrm{M} \pm \mathrm{sd}$, где $\mathrm{M}$ - среднее значение, sd - стандартное отклонение, при распределении, отличном от нормального - медианы и интерквартильного размаха (Me [25;75]). При анализе качественных данных в

\section{Медикаментозная терапия в группах пациентов}

\begin{tabular}{|c|c|c|c|c|}
\hline \multicolumn{2}{|l|}{ Показатель } & $\begin{array}{c}\text { I группа } \\
(<24 \text { мес, } \mathrm{n}=19)\end{array}$ & $\begin{array}{c}\text { II группа } \\
(>24 \text { мес, } n=63)\end{array}$ & $\begin{array}{l}\text { Р между } \\
\text { группами }\end{array}$ \\
\hline \multirow{2}{*}{$\begin{array}{l}\text { Антиаритмические } \\
\text { препараты, \% }\end{array}$} & исходно & 0 & $18(28,6)$ & 0,008 \\
\hline & в динамике & $2(10,5)$ & $19(30,2)$ & 0,115 \\
\hline \multirow{2}{*}{ Амиодарон, \% } & исходно & 0 & $14(22,2)$ & 0,036 \\
\hline & в динамике & $1(5,3)$ & $13(20,6)$ & 0,044 \\
\hline \multirow{2}{*}{ Соталол, \% } & исходно & 0 & $4(6,4)$ & 0,294 \\
\hline & в динамике & $1(5,3)$ & $6(9,5)$ & 0,660 \\
\hline \multirow{2}{*}{ AMKР, \% } & исходно & $17(89,5)$ & $53(84,1)$ & 0,563 \\
\hline & в динамике & $17(89,5)$ & $53(84,1)$ & 0,563 \\
\hline \multirow{2}{*}{ Диуретики, \% } & исходно & $17(89,5)$ & $28(44,4)$ & 0,001 \\
\hline & в динамике & $16(84,2)$ & $60(95,2)$ & 0,799 \\
\hline \multirow{2}{*}{$\begin{array}{l}\text { Блокаторы } \\
\text { Са-каналов, \% }\end{array}$} & исходно & $3(15,8)$ & $13(20,6)$ & 0,640 \\
\hline & в динамике & $4(21,1)$ & $17(27,0)$ & 0,825 \\
\hline \multirow{2}{*}{ БАБ, $\%$} & исходно & $19(100,0)$ & $59(93,7)$ & 0,260 \\
\hline & в динамике & $16(84,2)$ & $56(88,0)$ & 0,372 \\
\hline \multirow{2}{*}{ Дигоксин, \% } & исходно & $8(42,1)$ & $15(23,8)$ & 0,120 \\
\hline & в динамике & $5(26,3)$ & $14(22,2)$ & 0,493 \\
\hline \multirow{2}{*}{$\begin{array}{l}\text { Антикоагулянты, } \\
\%\end{array}$} & исходно & $8(42,1)$ & $28(44,4)$ & 0,857 \\
\hline & в динамике & $9(47,4)$ & $30(47,6)$ & 0,618 \\
\hline \multirow{2}{*}{ Дезагреганты, \% } & исходно & $10(52,6)$ & $34(54,0)$ & 0,918 \\
\hline & в динамике & $8(42,1)$ & $29(46,0)$ & 0,857 \\
\hline \multirow{2}{*}{ ИАПФ или БРА, \% } & исходно & $19(100,0)$ & $63(100,0)$ & 1,000 \\
\hline & в динамике & $16(84,2)$ & $61(96,8)$ & 0,799 \\
\hline \multirow{2}{*}{ Статины, \% } & исходно & $15(78,9)$ & $19(30,3)$ & $<0,001$ \\
\hline & в динамике & $14(73,7)$ & $50(79,4)$ & 0,630 \\
\hline
\end{tabular}

Примечание: АМКР - антагонисты минералокортикоидных рецепторов; БАБ $\beta$-адреноблокаторы; ИАПФ - ингибиторы ангиотензин-превращающего фермента; БРА - блокаторы ренинангиотензиновых рецепторов. несвязанных группах был использован критерий Хиквадрат. Для сравнения количественных показателей в несвязанных группах при их нормальном распределении был использован t-критерий Стьюдента, при отличном от нормального - критерий Манн-Уитни, в связанных группах - парный t-критерий Стьюдента либо критерий Вилкоксона. Различия считались значимыми при $\mathbf{p}<0,05$. Выживаемость оценивали по методу Каплан-Мейера. ROC-анализ и логистическую регрессию применили для выявления факторов, ассоциированных с поздним ответом на СРТ.

\section{ПОЛУЧЕННЫЕ РЕЗУЛЬТАТЫ}

По сроку наступления лучшего ответа на СРТ, оцененного ретроспективно по максимальному снижению КСОЛЖ, пациенты были разделены на 2 группы: 1 группа (n=19) - $\leq 24$ месяцев (средний срок 14,0[8,0;21,0] месяцев), 2 группа ( $\mathrm{n}=63)$ - >24 месяцев (средний срок $59[43,0 ; 84,0]$ месяцев). Клиническая характеристика сравниваемых групп представлена в табл. 1, 2 .

Группы были сопоставимы по возрасту и основным клиническим параметрам. В динамике не было выявлено значимых различий между исследуемыми

таблица 2. группами ФК СН по NYHA и теста 6-мин. ходьбы. Была отмечена большая частота назначения диуретиков и статинов в 1 группе, антиаритмических препаратов во 2 группе.

\section{Нарушения ритма сердиа}

СМЭКГ в динамике было выполнено у 17 (89,5\%) больных в 1 группе и $41(65,1 \%)$ во 2 группе. Частота встречаемости фибрилляции предсердий в группах была практически одинаковой. Значимых различий между группами в общем количестве зарегистрированных желудочковых экстрасистол (ЖЭ), а также количестве ЖЭ в 1 час. исследования, ни исходно, ни в динамике не было отмечено. Однако необходимо отметить, что показатель количества ЖЭ> 10 в 1 час., являющийся прогностически неблагопрятным, был отмечено исходно во 2 группе и в динамике в 1 группе. Только в группе позднего ответа на СРТ в динамике наблюдалось значимое снижение как общего количества ЖЭ, так и ЖЭ в 1 час.

\section{Параметры ЭхокГ} в динамике

Исходно не было выявлено различий параметров ЭхоКГ между группами (табл. 3). На фоне СРТ в обеих группах наблюдалась значимая по- 
ложительная динамика показателей ЭхоКГ. Однако в динамике во 2 группе были отмечены меньшие конечно-систолический и конечно-диастолический размеры ЛЖ (КСРЛЖ, КДРЛЖ), конечно-систолический и конечно-диастолический объемы ЛЖ (КДОЛЖ) (рис. 1).

Динамика лабораторных показателей на фоне CPT

Динамика иследуемых биомаркеров в группах представлена в табл. 4. Средние уровни катехоламинов (КА) были в пределах референтных значений. Во 2 группе исходно были выявлены более высокие концентрации Адр. Динамика уровней КА в группах была противоположной. В 1 группе при отсутствии изменений уровня Адр была отмечена тенденция к повышению НАдр, концентрация которого на фоне СРТ была выше, чем во 2 группе. Во 2 группе, наряду со значимым снижением уровня Адр, уменьшение концентрации НАдр было не достоверным. Однако степень изменения уровня НАдр была значимо противоположной: повышалась в 1 группе и снижалась во 2 группе.

На фоне СРТ в группах было отмечено снижение уровня ИЛ- $1 \beta$, ИЛ-6, ФНО- $\alpha$, при отсутствии динамики уровня СРБ. Исходно во 2 группе была выявлена более высокая концентрация ИЛ10, значимо снижающаяся на фоне СРТ. Степень изменения ИЛ-10 повышалась в 1 группе и снижалась во 2 группе.

Уровни NT-proBNP в группах были выше референтных значений. Значимых различий между группами как исходно, так и на фоне СРТ, а также достоверной динамики уровня NT-proBNP в группах не было выявлено.

Уровни ТIMP-1 в группах были выше референтных значений. На фоне СРТ только во 2 группе было отмечено снижение уровня ТIMP-1 и увеличение индекса МMP-9/TIMP1. При отсутствии динамики отношения МMP-9/TIMP-4 в группах, его значение во 2 группе на фоне СРТ было выше.

\section{оценка}

\section{продолжительности} жсизни и 5-летней выживаемости

Во 2 группе наряду с большим средним сроком луч- шего ответа на СРТ $(13,5 \pm 7,0$ и $63,5 \pm 26,3$ мес. соответственно, $\mathrm{p}<0,001)$, был отмечен в 2 раза больший средний период наблюдения (45,8 $\pm 20,3$ мес. и 94,9 $\pm 35,9$ мес. соответственно, $\mathbf{p}<0,001)$. Методом Каплан-Мейера было выявлено, что в группе пациентов с поздним сроком суперответа (>24 месяцев) ни один из пациентов не умер в течение 5 лет, выживаемость в 1 группе составила 50\% (Log-Rank test $<0,001)$ (рис. 2).

\section{Выявление факторов, ассоциированных с поздним ответом на СРT}

При проведении логистической регрессии для выявления факторов, ассоциированных с поздним ответом на СРТ, в исходную совокупность независи-

Таблица 3.

Показатели эхокардиографии в динамике

\begin{tabular}{|c|c|c|c|c|}
\hline Показатель & & $\begin{array}{c}\text { I группа } \\
(<24 \text { мес, } \mathrm{n}=19)\end{array}$ & $\begin{array}{c}\text { II группа } \\
(>24 \text { мес, } n=63)\end{array}$ & $\begin{array}{c}\text { Р между } \\
\text { группами }\end{array}$ \\
\hline \multirow{3}{*}{$\begin{array}{l}\text { Левое предсердие, } \\
\text { мм }\end{array}$} & исходно & $49,3 \pm 4,2$ & $50,0 \pm 5,3$ & 0,537 \\
\hline & в динамике & $44,3 \pm 3,8$ & $45,0 \pm 7,1$ & 0,593 \\
\hline & Р в группе & $<0,001$ & $<0,001$ & \\
\hline \multirow{3}{*}{$\begin{array}{ll}\text { Правое } & \text { предсер- } \\
\text { дие, мл } & \end{array}$} & исходно & $85,2 \pm 31,4$ & $75,7 \pm 27,0$ & 0,262 \\
\hline & в динамике & $62,8 \pm 17,0$ & $65,3 \pm 26,9$ & 0,660 \\
\hline & Р в группе & $<0,001$ & $<0,001$ & \\
\hline \multirow{3}{*}{$\begin{array}{l}\text { Правый } \text { желудо- } \\
\text { чек, мм }\end{array}$} & исходно & $30,4 \pm 4,8$ & $29,6 \pm 4,5$ & 0,628 \\
\hline & в динамике & $27,4 \pm 3,0$ & $27,4 \pm 2,8$ & 0,863 \\
\hline & Р в группе & 0,002 & $<0,001$ & \\
\hline \multirow{3}{*}{ КСРЛЖ, мм } & исходно & $58,8 \pm 8,4$ & $58,4 \pm 6,5$ & 0,891 \\
\hline & в динамике & $46,7 \pm 7,3$ & $41,9 \pm 7,7$ & 0,041 \\
\hline & Р в группе & 0,001 & $<0,001$ & \\
\hline \multirow{3}{*}{ КДРЛЖ, мм } & исходно & $68,8 \pm 8,6$ & $66,4 \pm 6,5$ & 0,256 \\
\hline & в динамике & $59,9 \pm 6,8$ & $56,3 \pm 6,7$ & 0,049 \\
\hline & Р в группе & $<0,001$ & $<0,001$ & \\
\hline \multirow{3}{*}{ КСОЛЖ, мл } & исходно & $176,5 \pm 52,9$ & $157,5 \pm 42,7$ & 0,166 \\
\hline & в динамике & $95,5 \pm 38,1$ & $75,3 \pm 27,8$ & 0,014 \\
\hline & Р в группе & $<0,001$ & $<0,001$ & \\
\hline \multirow{3}{*}{ КДОЛЖ, мл } & исходно & $250,8 \pm 72,8$ & $229,0 \pm 51,7$ & 0,237 \\
\hline & в динамике & $178,5 \pm 51,0$ & $151,5 \pm 40,3$ & 0,045 \\
\hline & Р в группе & $<0,001$ & $<0,001$ & \\
\hline \multicolumn{2}{|l|}{ МЖП, мм } & $10,5 \pm 1,7$ & $10,7 \pm 1,3$ & 0,458 \\
\hline \multicolumn{2}{|l|}{ ЗСЛЖ, мм } & $10,6 \pm 1,2$ & $10,3 \pm 1,2$ & 0,429 \\
\hline \multirow{3}{*}{ ФВЛЖ, \% } & исходно & $29,8 \pm 4,5$ & $31,8 \pm 5,0$ & 0,133 \\
\hline & в динамике & $47,5 \pm 8,9$ & $50,2 \pm 8,7$ & 0,261 \\
\hline & Р в группе & $<0,001$ & $<0,001$ & \\
\hline \multirow{3}{*}{ СДЛА, мм рт.ст. } & исходно & $46,4 \pm 10,9$ & $40,8 \pm 10,1$ & 0,068 \\
\hline & в динамике & $29,9 \pm 7,4$ & $31,3 \pm 12,3$ & 0,703 \\
\hline & Р в группе & $<0,001$ & $<0,001$ & \\
\hline
\end{tabular}

Примечание: КСРЛЖ - конечно-систолический размер левого желудочка; КДРЛЖ - конечно-диастолический размер левого желудочка; КСОЛЖ - конечно-систолический объем левого желудочка; КДОЛЖ - конечно-диастолический объем левого желудочка; МЖП - межжелудочковая перегородка; ЗСЛЖ - задняя стенка левого желудочка; ФВЛЖ - фракция выброса левого желудочка; СДЛА систолическое давление в легочной артерии. 
мых переменных были включены параметры, значимо различающиеся между группами в сроке лучшего ответа - КСРЛЖ, КДРЛЖ, КСОЛЖ, КДОЛЖ, индекс MМР-9/TIMР-4 и уровень НАдр, который с помощью ROC-кривой разделили на две категории: $<2,55$ нг/мл и $\geq 2,55$ нг/мл. Точка разделения 2,55 нг/мл соответствовала наибольшей чувствительности (80\%), специфичности $(60 \%)$ и $\mathrm{AUC}=0,693(\mathrm{p}=0,011)$ в предсказании срока ответа. Доля пациентов с уровнем НАдр $<2,55$ нг/мл в группах составила 21,1\% и 59,7\% соответственно ( $\mathrm{p}=0,003)$. С поздним ответом на СРТ оказался связанным уровень НАдр: ОШ 8,0 (95\%ДИ 1,5-42,8), $\mathrm{p}=0,015$. При наличии показателя НАдр менее 2,55 нг/ мл шанс более позднего ответа увеличивается в 8 раз.

\section{ОБСУЖДЕНИЕ ПОЛУЧЕННЫХ РЕЗУЛЬТАТОВ}

Ранее проведенными исследованиями, была отмечена ассоциация позднего ответа на СРТ с лучшей выживаемостью [6], в связи с чем была выдвинута гипотеза, что в клинически сходных группах СР с различным сроком ответа на СРТ лежит различная динамика биомаркеров ключевых звеньев патогенеза ХCH - активности процесса фиброза, симпато-адреналовой, иммунной, нейро-гуморальной активации.

Более трех десятилетий назад анализ уровней КА при ХСН привел к изменению парадигмы лечения этого состояния. J.Cohn et al. (1984) впервые, исследовав 106 пациентов с систолической сердечной недостаточностью, выявил повышенный уровень НАдр в плазме, который являлся независимым предиктором смертности [9]. В последующем прогностическая значимость НАдр была подтверждена в исследованиях Val-HeFt [10], ADMIRE-HF [11] и других [12], в то время как Адр, как правило, не анализировался. Однако активация надпочечников является одним из ключевых механизмов, вовлеченных в симпатическое возбуждение при ХСН. Мозговое вещество надпочечников секретирует примерно 80\% Адр и 20\% НАдр [13]. Практически, весь Адр плазмы имеет надпочечниковое происхождение. Вклад КА надпочечников в прогрессирование ХCH еще предстоит уточнить. G.Vergaro et al. (2019) показали в своей работе гетерогенность нейрогормональной регуляции у больных с ХСН [14]. В исследовании циркулирующие уровни нейрогормонов (NT-proBNP, ренина, альдостерона, НАдр), но не Адр, имели тенденцию к увеличению параллельно с выраженностью симптомов сердечной недостаточности, однако, часто были ниже контрольных значений. В группе больных с хронической систолической сердечной недостаточностью повышенные уровни NT-proBNP наблюдались в $97 \%$ случаев, НАдр в 53\%, а Адр всего лишь в 16\%. В течение 5-летнего периода наблюдения выживаемость снижалась с увеличением числа нейрогормонов с повышенным уровнем.

В нашем исследовании, с учетом референтных значений КА, в исследуемых группах не было отмечено повышенных плазменных уровней КА ни исходно, ни в динамике. Однако базальный уровень симпато-адреналовой регуляциии и ее динамика на фоне СРТ имели значимые различия в группах. Исходно более высокая концентрация КА в плазме у больных 2 группе, вероятно, может быть следствием более выраженного нарушения сложного механизма регуляции метаболизма КА, часто обусловленного коморбидной патологией (дисфункция щитовидной железы, надпочечников и др.), которая в нашей работе не анализировалась [15]. Увеличение уровня НАдр и отсутствие динамики Адр в 1 группе сопровождалось меньшим обратным ремоделированием сердца на фоне СРТ, что могло быть обусловлено метаболическими эффектами КА. В эксперименте инфузия КА вызывает экспрес-

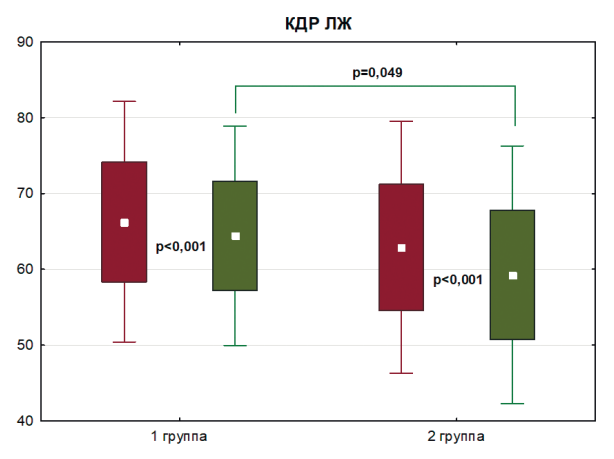

кдо лж

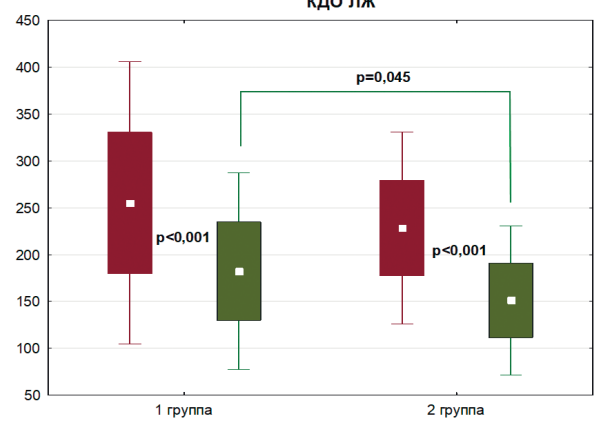

ксР лж

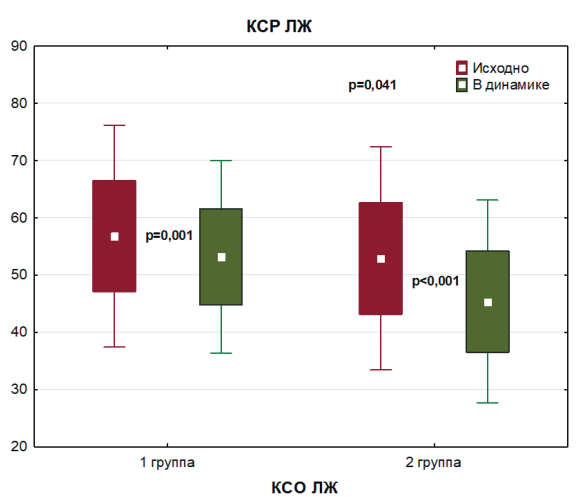

ксо лж

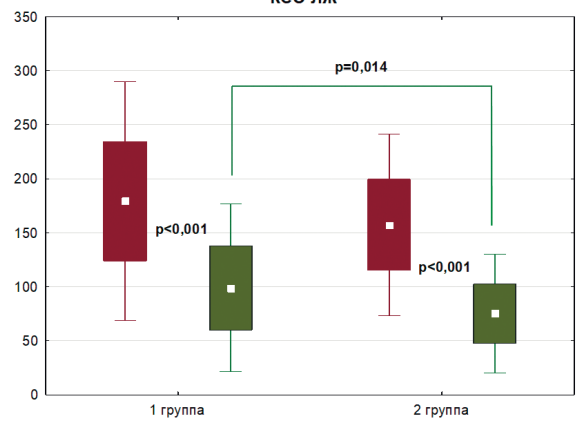

Рис. 1. Динамика значимо различающихся показателей эхокардиографии (КДРЛЖ, КСРЛЖ, КДОЛЖ, КСОЛЖ) в группах с различным сроком ответа. сию главного регулятора клеточного старения - белка р53, способствующего сердечной дисфункции путем регуляции клеточного цикла или апоптоза [16]. НАдр посредством передачи сигналов р53 провоцирует воспаление сердца путем активации молекул межклеточной адгезии-1 (ICAM1) и экспрессии интегрина в эндотелиальных клетках и макрофагах. Эндотелиальное воспаление вызывает накопление периваскулярных макрофагов, что способствует повреждению тканей, а также приводит к пролиферации фибробластов, трансформирующихся в миофибробласты и вызывающих фиброз миокарда. Симпато-адреналовые влияния при $\mathrm{XCH}$, опосредуемые преимущественно через экспрессию $\beta_{2}$-адренорецеп- 
Динамика лабораторных показателей в группах пациентов

Таблица 4.

\begin{tabular}{|c|c|c|c|c|c|}
\hline Показатель & & $\begin{array}{c}\text { Референтные } \\
\text { значения }\end{array}$ & $\begin{array}{c}\text { I группа } \\
(<24 \text { мес, } \mathrm{n}=19)\end{array}$ & $\begin{array}{c}\text { II группа } \\
(>24 \text { мес, } n=63)\end{array}$ & $\begin{array}{c}\text { Р между } \\
\text { группами }\end{array}$ \\
\hline \multirow{3}{*}{ Адр, нг/мл } & исходно & \multirow{3}{*}{$0,018-6,667$} & $1,1[0,1 ; 2,2]$ & $2,1[0,7 ; 3,4]$ & 0,049 \\
\hline & динамика & & $1,4[0,1 ; 2,3]$ & $0,4[0,1 ; 1,6]$ & 0,388 \\
\hline & Р в группе & & 0,887 & 0,024 & \\
\hline \multicolumn{2}{|l|}{$\Delta$ Адр, нг/мл } & - & $0,1[-0,9 ; 0,9]$ & $-1,0[-2,2 ; 0]$ & 0,311 \\
\hline \multirow{3}{*}{ НАдр, нг/мл } & исходно & \multirow{3}{*}{$0,093-33,333$} & $1,1[0,2 ; 7,0]$ & $5,9[0,6 ; 21,1]$ & 0,061 \\
\hline & динамика & & $7,8[2,9 ; 17,2]$ & $1,1[0,2 ; 8,7]$ & 0,011 \\
\hline & Р в группе & & 0,069 & 0,115 & \\
\hline \multicolumn{2}{|l|}{$\Delta$ НАдр, нг/мл } & - & $4,0[-5,2 ; 14,3]$ & $-1,2[-11,6 ; 4,0]$ & 0,015 \\
\hline \multirow{3}{*}{ NT-proBNP, пг/мл } & исходно & \multirow{3}{*}{ До 125} & $1957,0[997,8 ; 4637,5]$ & $1400,0[861,5 ; 3617,5]$ & 0,093 \\
\hline & динамика & & $502,5[307,5 ; 1356,5]$ & $542,0[215,0 ; 1732,5]$ & 0,917 \\
\hline & Р в группе & & 0,218 & 0,069 & \\
\hline \multirow{3}{*}{ ИЛ-1 $\beta$, пг/мл } & исходно & \multirow{3}{*}{$0-5$} & $2,7[2,3 ; 4,4]$ & $3,9[3,4 ; 4,4]$ & 0,600 \\
\hline & динамика & & $3,2[2,6 ; 4,0]$ & $2,7[2,3 ; 3,6]$ & 0,609 \\
\hline & Р в группе & & & 0,064 & $<0,001$ \\
\hline \multirow{3}{*}{ ИЛ-6, пг/мл } & иходно & \multirow{3}{*}{$0-9,7$} & $2,6[2,4 ; 3,4]$ & $2,9[2,4 ; 5,0]$ & 0,784 \\
\hline & динамика & & $2,0[1,4 ; 3,1]$ & $2,5[2,1 ; 2,8]$ & 0,509 \\
\hline & Р в группе & & 0,047 & 0,030 & \\
\hline \multirow{3}{*}{ ИЛ-10, пг/мл } & исходно & \multirow{3}{*}{$0-9,1$} & $1,8[1,5 ; 3,5]$ & $3,9[2,7 ; 5,1]$ & 0,019 \\
\hline & динамика & & $2,6[2,1 ; 3,8]$ & $1,9[1,6 ; 2,7]$ & 0,159 \\
\hline & Р в группе & & 0,579 & 0,003 & \\
\hline \multicolumn{2}{|l|}{$\Delta$ ИЛ-10, пг/мл } & - & $0,4[-0,6 ; 1,2]$ & $-2,3[-3,4 ;-0,5]$ & 0,007 \\
\hline \multirow{3}{*}{ ФНО- $\alpha$, пг/мл } & исходно & \multirow{3}{*}{ До 8,11 } & $8,1[4,3 ; 11,3]$ & $9,2[7,5 ; 10,4]$ & 0,832 \\
\hline & динамика & & $5,4[4,4 ; 6,3]$ & $4,3[3,2 ; 6,0]$ & 0,331 \\
\hline & Р в группе & & 0,047 & $<0,001$ & \\
\hline \multirow{3}{*}{ СРБ, мг/мЛ } & исходно & \multirow{3}{*}{$<3,0$} & $2,8[0,4 ; 7,2]$ & $2,8[1,6 ; 6,9]$ & 0,945 \\
\hline & динамика & & $3,1[1,2 ; 4,3]$ & $3,0[1,1 ; 6,0]$ & 0,469 \\
\hline & Р в группе & & 0,294 & 0,798 & \\
\hline \multirow{3}{*}{ ММР-9, нг/мЛ } & исходно & \multirow{3}{*}{$2,0-139,4$} & $160,8[139,4 ; 228,3]$ & $149,4[113,1 ; 198,3]$ & 0,343 \\
\hline & динамика & & $171,6[133,9 ; 221,8]$ & $197,6[152,0 ; 240,4]$ & 0,136 \\
\hline & Р в группе & & 0,536 & 0,122 & \\
\hline \multirow{3}{*}{ ТІМР-1, нг/мЛ } & исходно & \multirow{3}{*}{$92-116$} & $210,5[156,4 ; 365,6]$ & $297,4[168,7 ; 439,2]$ & 0,329 \\
\hline & динамика & & $182,6[160,5 ; 288,9]$ & $181,9[147,8 ; 264,5]$ & 0,887 \\
\hline & Р в группе & & 0,173 & 0,010 & \\
\hline \multirow{3}{*}{ ТІМР-4, нг/мЛ } & исходно & \multirow{3}{*}{$214-10000$} & $2418,0[1910,4 ; 3012,9]$ & $2435,2[1827,1 ; 3571,8]$ & 0,389 \\
\hline & динамика & & $2529,6[1930,3 ; 3578,0]$ & $2127,8[1711,2 ; 278156]$ & 0,096 \\
\hline & Р в группе & & 0,371 & 0,220 & \\
\hline & исходно & & $0,857[0,440 ; 1,179]$ & $0,494[0,312 ; 0,867]$ & 0,081 \\
\hline MMP-9/TIMP-1 & динамика & - & $0,666[0,516 ; 1,089]$ & $0,932[0,591 ; 1,3918]$ & 0,344 \\
\hline & Р в группе & & 0,874 & 0,023 & \\
\hline & исходно & & $0,076[0,060 ; 0,102]$ & $0,062[0,036 ; 0,086]$ & 0,410 \\
\hline MMP-9/TIMP-4 & динамика & - & $0,058[0,044 ; 0,091]$ & $0,092[0,064 ; 0,111]$ & 0,013 \\
\hline & Р в группе & & 0,159 & 0,327 & \\
\hline
\end{tabular}

Примечание: ИЛ - интерлейкин; ФНО- $\alpha$ - фактор некроза опухоли $\alpha$; СРБ - С-реактивный белок; NT-proBNP N-концевой фрагмент натрийуретического пептида; MМР-9 - матриксная металлопротеиназа 9; TIMP-1 и 4 - тканевые ингибиторы матриксной металлопротеиназы 1 и 4. 
торов, связанны с повышенной продукцией активных форм кислорода и ухудшением сердечной функции [17]. Длительная избыточная стимуляция $\beta$-адренорецепторов индуцирует синтез и секрецию факторов роста и цитокинов в кардиомиоцитах, которые влияют на активацию фибробластов сердца, увеличивающих синтез коллагена и ведущих к фиброзу сердца [18]. Результаты нашего исследования свидетельствуют о гетерогенности вегетативной дисфункции и различном модулирующем влиянии СРТ на симпато-адреналовую активность в сравниваемых группах. Повышение симпато-адреналовой активации на фоне СРТ сопровождается меньшим обратным ремоделированием сердца, меньшей динамикой иммунного воспаления и худшим прогнозом.

Во 2 группе снижение симпато-адреналовой активности было сопряжено со снижением иммунной и нейро-гуморальной активации, о чем свидетельствует значимое снижение уровня цитокинов ИЛ- $1 \beta, 6,10$, ФНО- $\alpha$. Данные литературы свидетельствуют о способности цитокинов и других медиаторов воспаления через различные клеточные механизмы влиять на симпатическую активацию [19]. Активность иммунного воспаления в 1 группе тоже снижалась, однако, не так интенсивно, как во 2 группе. На фоне значимого снижения уровня ИЛ-6 и ФНО- $\alpha$ отсутствовала достоверная динамика ИЛ-1 $\beta$ и ИЛ-10. Установлено, что ИЛ-1 $\beta$ и ИЛ-6 вызывают активацию молекул ICAM1, регулирующих патологическое ремоделирование сердца путем опосредования провоспалительной инфильтрации лейкоцитов в левом желудочке, фиброза и дисфункции сердца [20]. Истинная роль ИЛ-10 в генезе ХCH, к сожалению, не ясна. В эксперименте на изолированных моноцитах больных с ХСН инкубация клеток с норэпинефрином приводила к экспрессии ИЛ-10 [21]. В нашем исследовании противоположная степень изменения ИЛ-10 в исследуемых группах была ассоциирована с различной динамикой симпато-адреналовой активности. Несмотря на ряд работ, показавших снижение уровня СРБ на фоне СРТ $[22,23]$, в исследуемых нами группах не было отмечено его значимой динамики. Иммуномодулирующее влияние СРТ было

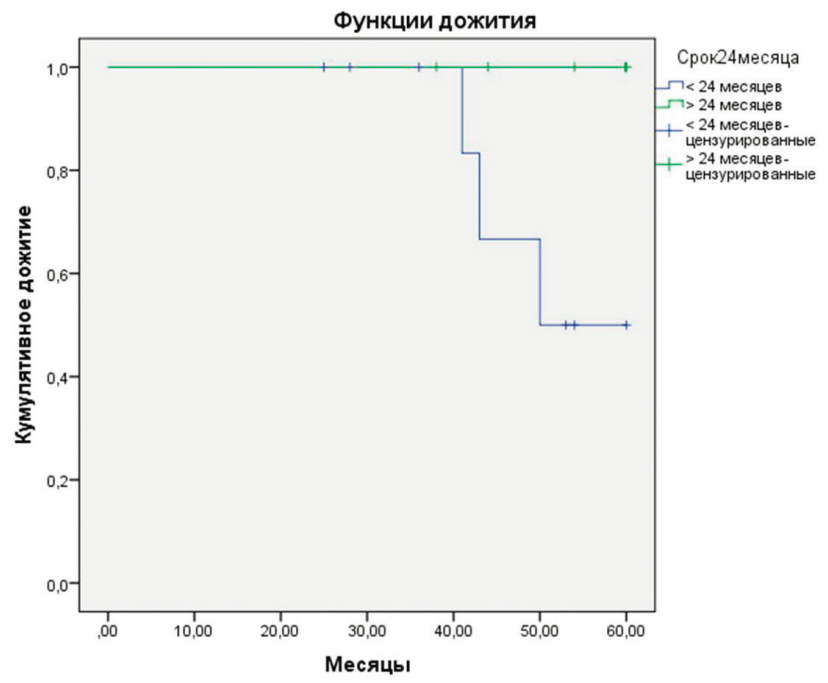

Рис. 2. График 5-летней выжниаемости больных с различным сроком суперответа (Log-Rank test <0,001). подтверждено целым рядом ранее проведенных исследований [24-26]. Результаты нашего исследования подтверждают ассоциацию снижения иммунной активации с эффективностью СРТ. Более выраженное снижение уровня цитокинов во 2 группе сопровождается большим обратным ремоделированием сердца на фоне СРТ и лучшим прогнозом.

Ранее была установлена связь концентрации TIMP-1 с тяжестью ХCH [27]. В обеих анализируемых группах концентрация TIMP-1 была выше референтных значений исходно и в динамике, что свидетельствует о тяжести исследуемой нами когорты больных. На фоне СРТ значимое снижение уровня TIMP-1, увеличение индекса МMP-9/TIMP-1, а также более высокий коэффициент MMP-9/TIMP-4 во 2 группе могут свидетельствовать о снижении активности миокардиального фиброзирования. Поскольку такой паттерн изменений биомаркеров фиброзирования выявлен в группе с лучшим прогнозом, вероятно, он имеет положительный физиологический смысл. В исследовании D.Bonnema et al. (2007) было обнаружено снижение отношений МMP-9/TIMP-1, MМР-9/TIMP-4 и MMP-2/ TIMP-4 во время старения, что указывает на сниженную способность к деградации экстрацеллюлярного кардиального матрикса с возрастом и способствует развитию интерстициального фиброза [28]. Вероятно, коэффициенты ММР-9/TIMP-1 и ММР-9/ТIMP-4 отражают более сохранную способность к реконструкции экстрацеллюлярного кардиального матрикса и более высокие адаптивные возможности пациентов 2 группе.

Описанное в литературе снижение частоты мотивированных срабатываний кардиовертера-дефибриллятора у СР [2, 3, 5] на фоне выявленного нами снижения симпато-адреналовой, иммунной, нейро-гуморальной активации и процесса миокардиального фиброобразования выглядит вполне закономерно. Необходимо отметить, что, выявленная нами исходно более высокая симпато-адреналовая активация во 2 группе сопровождалась большей частотой ЖЭ по данным СМЭКГ и более частым назначением антиаритмических препаратов. В динамике снижение плазменного уровня КА в группе позднего ответа на СРТ было сопряжено со значимым снижением ЖЭ. Прогностически неблагоприятный показатель количества ЖЭ $>10$ в час. коррелировал с симпато-адреналовой активацией: наблюдался исходно у больных 2 группе и в динамике у больных 1 группе. Необходимо отметить, что наиболее часто назначаемым антиаритмическим препаратом во 2 группе, как исходно, так и в динамике был амиодарон, прогностическая значимость которого по данным литературы неоднозначна [29]. Существует мнение, что амиодарон не влияет на прогноз больных с ХCH и может применяться для уменьшения симптомов желудочковых аритмий после инфаркта миокарда (класс рекомендаций IIb, уровень доказанности В). Однако существует также мнение, что применение амиодарона связано с повышенным риском смерти от ХCH независимо от ФК. В исследовании C.Torp-Pedersen et al. (2007) амиодарон повышал риск смерти в 1,5 раза $(\mathrm{p}<0,001)$, причем различия были в основном обусловлены риском смерти из-за ХCH $(\mathrm{OP}=2,4 ; \mathrm{p}<0,001)$, в 
то время как риск внезапной смерти не имел различий $(\mathrm{OP}=1,07 ; \mathrm{p}=0,7)$ [30]. В исследовании Sudden Cardiac Death in Heart Failure Trial анализ данных в зависимости от ФК ХСН показал, что при II ФК эффект амиодарона был равен эффекту плацебо, но при III ФК амиодарон повышал риск смерти на 44\% [31].

У больных с СРТ в исследовании E.C.Adelstein et al. (2019) применение амиодарона было связано с меньшим сужением QRS, меньшим улучшением ФВЛЖ, большим риском смерти [32]. Учитывая противоречивость данных литературы о прогностической значимости амиодарона у больных с ХCH, необходимо применять препарат с большой осторожностью и под тщательным наблюдением за пациентами. В нашем исследовании, учитывая лучшую выживаемость пациентов 2 группе, влияние антиаритмических препаратов явно не было определяющим. Прогностическим было влияние снижение НАдр.

Анализируя лечение в исследуемых группах необходимо отметить, что частота приема дигоксина исходно в 1 группе, несмотря на отсутствие значимых различий, была практически в 2 раза выше и могла бы повлиять на худшую выживаемость пациентов этой группы. Однако одинаковые доли пациентов, принимающих дигоксин в конце исследования, явно исключают такую возможность. Статины с их многочисленными плейотропными эффектами не могли способствовать более низкой выживаемости больных 1 группы.
Уменьшением активности ключевых механизмов патогенеза ХСН можно объяснить и большее обратное ремоделирование камер сердца в группе с поздним суперответом на СРТ. Данные литературы свидетельствуют о лучшем прогнозе у СР, которые практически восстановили функцию сердца до нормальной, в сравнении с другими реципиентами СРТ [2, 33]. J.Rickard et al. (2014) продемонстрировали, что лучшая 5-летняя выживаемость СР по сравнению с другими респондентами СРТ стала очевидной только через 2 года после имплантации СРТ-устройств [34]. Большая часть анализируемых нами СР (77\%) показала наилучший функциональный ответ на СРТ в сроке, превышающем 24 месяца, причем, более поздний ответ был ассоциирован с лучшей 5-летней выживаемостью.

Основные ограничения исследования - ретроспективный дизайн и небольшое количество исследованных больных.

\section{ЗАКЛЮЧЕНИЕ}

Поздний ответ на СРТ сопровождался увеличением продолжительности жизни, лучшей 5-летней выживаемостью, ассоциированными с большим обратным ремоделированием сердца, снижением активности процесса развития фиброза, иммунной, нейро-гуморальной и симпато-адреналовой активации. При уровне НАдр менее 2,55 нг/мл шанс позднего ответа увеличивался в 8 раз.

\section{ЛИТЕРАТУРА}

1. Priori SG, Blomström-Lundqvist C, Mazzanti A, et al. 2015 ESC Guidelines for the management of patients with ventricular arrhythmias and the prevention of sudden cardiac death The Task Force for the Management of Patients with Ventricular Arrhythmias and the Prevention of Sudden Cardiac Death of the European Society of Cardiology (ESC) Endorsed by: Association for European Paediatric and Congenital Cardiology (AEPC). Europace. 2015;17(11): 1601-87. https://doi.org/10.1093/europace/ euv319.

2. Killu AM, Mazo A, Grupper A, et al. Super-response to cardiac resynchronization therapy reduces appropriate implantable cardioverter defibrillator therapy. Europace. 2018;20(8): 1303-11. https://doi.org/10.1093/europace/ eux235.

3. Chatterjee NA, Roka A, Lubitz SA, et al. Reduced appropriate implantable cardioverter-defibrillator therapy after cardiac resynchronization therapy-induced left ventricular function recovery: a meta-analysis and systematic review. Eur Heart J. 2015;36(41): 2780-9. https://doi. org/10.1093/eurheartj/ehv373.

4. Rohit MK, Krishnappa D. Incidence and predictors of super-response to cardiac resynchronization therapy. Indian Heart J. 2019;71(4): 334-7. https://doi.org/10.1016/j. ihj.2019.09.007.

5. Cvijic M, Antolic B. Super-response to cardiac resynchronization therapy reduces appropriate implantable cardioverter-defibrillator therapy: comment. Europace. 2019;21(1): 178. https://doi.org/10.1093/europace/euy211. 6. Soldatova AM, Kuznetsov VA, Krinochkin DV, et al. Late best response to cardiac resynchronization therapy is associated with better survival of patients with congestive heart failure. Curr Res Cardiol. 2017;4(4): 58-60. ISSN: 2368-0512.

7. Li KB, Qian ZY, Qian XS, et al. Cardiac electrical and mechanical synchrony of super-responders to cardiac resynchronization therapy. Chin Med J (Engl). 2020;133(2): 141-7. https://doi.org/10.1097/CM9.0000000000000600.

8. Whinnett ZI, Davies JER, Lane RE, et al. Echocardiographic methods for selecting patients suitable for biventricular pacing therapy. Minerva Cardioangiol. 2005;53(3): 211-20. PMID:16003255.

9. Cohn JN, Levine TB, Olivari MT, et al. Plasma norepiniphrine as a guide to prognosis in patients with chronic congestive heart failure. $N$ Engl J Med. 1984 Sep 27;311(13): 819-23. https://doi.org/10.1056/NEJM198409273111303. 10. Latini R, Masson S, Anand I, et al. The comparative prognostic value of plasma neurohormones at baseline in patients with heart failure enrolled in Val-HeFT. Eur Heart J. 2004;25(4): 292-9. https://doi.org/10.1016/j. ehj.2003.10.030.

11. Cohen-Solal A, Jacobson AF, Piña IL. Beta blocker dose and markers of sympathetic activation in heart failure patients: interrelationships and prognostic significance. ESC Heart Fail. 2017;4(4): 499-506. https://oi. org/10.1002/ehf2.12153.

12. Atsumi W, Tani S, Tachibana E, et al. Combined Evaluation of the Plasma Arginine Vasopressin and Noradrenaline Levels May be a Useful Predictor of the Prognosis of Patients with Acute Decompensated Heart Failure. Int Heart J. 2018;59(4): 791-801. https://doi.org/10.1536/ ihj.17-244. 
13. Tank AW, Lee Wong D. Peripheral and central effects of circulating catecholamines. Comprehensive Physiology. 2015;5: 1-15. https://doi.org/10.1002/cphy.c140007.

14. Vergaro G, Aimo A, Prontera C, et al. Sympathetic and renin-angiotensin-aldosterone system activation in heart failure with preserved, mid-range and reduced ejection fraction. Int J Cardiol. 2019;296: 91-7. https://doi. org/10.1016/j.ijcard.2019.08.040.

15. Streng KW, Nauta JF, Hans L. Hillege HL et al. Non-cardiac comorbidities in heart failure with reduced, mid-range and preserved ejection fraction. International Journal of Cardiology. 2018;271: 132-139. http://creativecommons.org/licenses/by-nc-nd/4.0.

16. Katsuumi G, Shimizu I, Yoshida Y, et al. Catecholamine-Induced Senescence of Endothelial Cells and Bone Marrow Cells Promotes Cardiac Dysfunction in Mice. Int Heart J. 2018;59(4): 837-44. https://doi.org/10.1536/ ihj.17-313.

17. Yoshida Y, Shimizu I, Katsuumi G, et al. p53-Induced inflammation exacerbates cardiac dysfunction during pressure overload. J Mol Cell Cardiol. 2015; 85: 183-98. https://doi.org/10.1016/j.yjmcc.2015.06.001.

18. Nuamnaichati N, Sato VH, Moongkarndi P, et al. Sustained $\beta$-AR stimulation induces synthesis and secretion of growth factors in cardiac myocytes that affect on cardiac fibroblast activation. Life Sci. 2018;193: 257-69. https:// doi.org/10.1016/j.lfs.2017.10.034.

19. Kenney MJ, Ganta CK. Autonomic Nervous System and Immune System Interactions. Compr Physiol. 2014;4(3): 1177-200. https://doi.org/10.1002/cphy. c130051.

20. Salvador AM, Nevers T, Velázquez F, et al. Intercellular Adhesion Molecule 1 Regulates Left Ventricular Leukocyte Infiltration, Cardiac Remodeling, and Function in Pressure Overload-Induced Heart Failure. $\mathrm{J} \mathrm{Am}$ Heart Assoc. 2016;5(3): e003126. https://doi.org/10.1161/ JAHA.115.003126.

21. Ng TM, Toews ML. Impaired norepinephrine regulation of monocyte inflammatory cytokine balance in heart failure. World J Cardiol. 2016;8(10): 584-89. https://doi. org/10.4330/wjc.v8.i10.584.

22. Kamioka M, Suzuki H, Yamada S, et al. High sensitivity C-reactive protein predicts nonresponders and cardiac deaths in severe heart failure patients after CRT implantation. Int Heart J. 2012;53(5): 306-12. https://doi. org/10.1536/ihj.53.306.

23. Chi CAI, Wei HUA, Li-Gang DING, et al. High sensitivity $\mathrm{C}$-reactive protein and cardfiac resynchronization therapy in patients with advanced heart failure. J Geriatr Cardiol. 2014;11(4): 296-302. https://doi.org/10.11909/j. issn. 1671-5411.2014.04.004.

24. Rordorf R, Savastano S, Sanzo A, et al. Tumor necrosis factor- $\alpha$ predicts response to cardiac resynchronization therapy in patients with chronic heart failure. Circ J. 2014;78(9): 2232-9. PMID: 24954238.

25. Osmancik P, Herman D, Stros P, et al. Changes and prognostic impact of apoptotic and inflammatory cyto- kines in patients treated with cardiac resynchronization therapy. Cardiology. 2013;124(3): 190-8. https://doi. org/10.1159/000346621.

26. Кузнецов ВА, Солдатова АМ, Енина ТН, и др. Натрийуретический пептид и медиаторы воспаления у пациентов с различным ответом на сердечную ресинхронизирующую терапию. Сердечная Недостаточность. 2015;16(2): 88-92 [Kuznetsov VA, Soldatova AM, Enina $\mathrm{TN}$, et al. Natriuretic peptide and inflammation mediators in patients with different responses to cardiac resynchronization therapy. Russian Heart Failure Journal. 2015;16(2): 88-92. (In Russ)]. ISSN1728-4651.

27. Тепляков АТ, Андриянова АВ, Пушникова ЕЮ, и др. Тканевой ингибитор матриксных металлопротеиназ -1 (ТIMР-1) как независимый маркер ишемического ремоделирования миокарда при хронической сердечной недостаточности. Сибирский медицинский журнал. 2014;29(2): 28-33. [Teplyakov AT, Andriyanova AV, Pushnikova EY, et al. Tissue inhibitor of metalloproteinase 1 (TIMP-1) as an independent marker of ischemic myocardial remodeling in heart failure. Siberian Medical J. 2014;29(2): 28-33 (In Russ)]. ISSN 2073-8552.

28. Bonnema DD, Webb CS, Pennington WR, et al. Effects of age on plasma matrix metalloproteinases (MMPs) and tissue inhibitor of metalloproteinases (TIMPs). J Card Fail. 2007;13: 530-40. https://doi.org/10.1016/j.cardfail.2007.04.010.

29. Тарловская ЕИ. Особенности лечения нарушений ритма сердца у пациентов с хронической сердечной недостаточностью. Кардиология. 2017;57(S1): 32332. [Tarlovskaya E. I. Peculiarities of therapy for heart rhythm disorders in patients with chronic heart failure. Kardiologiia. 2017;57(S1): 323-32 (In Russ)]. https://doi. org/10.18087/cardio.2391.

30. Torp-Pedersen C, Metra M, Spark P et al. The safety of amiodarone in patients with heart failure. J Card Fail. 2007;13(5): 340-5. https://doi.org/10.1016/j.cardfail.2007.02.009.

31. Bardy GH, Lee KL, Mark DB et al. Amiodarone or an implantable cardioverter-defibrillator for congestive heart failure. N Engl J Med. 2005;352(3): 225-37. https://doi. org/10.1056/ NEJMoa043399.

32. Adelstein EC, Althouse AD, Davis L et al. Amiodarone is associated with adverse outcomes in patients with sustained ventricular arrhythmias upgraded to cardiac resynchronization therapy-defibrillators. J Cardiovasc Electrophysiol. 2019;30(3): 348-356. https://doi.org/ 10.1111/ jce. 13828 .

33. Ghani A, Delnoy P, Adiyaman A, et al. Predictors and long-term outcome of super-responders to cardiac resynchronization therapy. Clin Cardiol. 2017;40: 292-9. https:// doi.org/10.1002/clc.22658.

34. Rickard J, Cheng A, Spragg D, et al. Durability of the survival effect of cardiac resynchronization therapy by level of left ventricular functional improvement: fate of "nonresponders". Heart Rhythm. 2014;11(3): 412-6. https://doi. org/10.1016/j.hrthm.2013.11.025. 